\title{
Research on Physical Education Curriculum New Model Based on Physical Education Cloud Computing
}

\author{
Nian Li \\ School of Physical Education, \\ Shaanxi Normal University, \\ Xi'an, China \\ Email:139913120@qq.com
}

\begin{abstract}
To make the physical education (PE) curriculum model more intelligent, a new PE curriculum model based on PE cloud computing was investigated. The basic framework of cloud computing and "PE education cloud" were discussed. The operation mode of "PE cloud" was designed, including registration, data entry, course mode and teaching content. Then a comparative analysis of "PE education cloud" and the traditional mode was made. Our analysis demonstrated that "PE education cloud" could greatly improve the efficiency of physical education classes for students in terms of their physical quality. In conclusion, the development of physical education curriculum should be dedicated to the requirements of students, and resources ought to be allocated on demand. Meanwhile, teaching contents should be more flexible, diverse and efficient.
\end{abstract}

Keywords-Cloud computing; physical education cloud; new curriculum model

\section{INTRODUCTION}

The PE circle has been actively exploring the reform of physical education in colleges and universities. In the process of exploration, many types of research on digital management have been proposed and investigated. However, these researches generally embed some digital management on the basis of the original college PE mode, and there is no overall discussion and re-planning of PE mode[1]. In the field of education, the research and application of cloud computing has become increasingly popular, and the allocation of resources on demand has brought new inspiration to the reform of education. Physical education, as the education form with physical activity as the means, has the commonality with other disciplines, and has the particularity of physical education[2]. Therefore, despite the research on cloud education attracts great attention, it cannot be integrated directly into physical education. That is to say, "PE education cloud" is still in need of new development and design. Currently, the research and discussion of "PE education cloud" worldwide is still in the embryonic stage, and there are no conclusive research results yet [3]. Based on cloud computing technology, this study was aimed at breaking the framework of traditional PE mode, building a model of "PE education cloud" according to the basic theory of physical education, and designing and exploring the future mode of college PE, with respect to providing references for future PE education reform.

\section{BACKGROUND INFORMATION}

From the basic understanding of the curriculum, the basic meaning of the course refers to the course content and process of the school [4]. "Curriculum" refers to the course, that is, the content of education, or the curriculum plan. "Course" refers to the procedure, process and progress. Through the analysis of a large number of relevant literature, we summarized the latest and most typical five types of college PE curriculum implementation and management modes. They are triguaiacyl type, integrated type, parallel type, three-section type and club type [5]. In some USA colleges and universities, there is no socalled physical education curriculum. Their physical education is achieved through extracurricular activities, student interest clubs and PE competition clubs. American students advocate the values of body and fitness and have the consciousness of independent exercise. The supporting facilities for physical training are relatively complete, and extracurricular activities are well carried out. Teachers only need to provide scientific guidance and evaluation for these activities without necessary supervison [6]. China has the largest population in the world, and the distribution of educational resources is uneven, leading to the lack of physical education in colleges and universities. This phenomena cannot reflect the scientific nature of PE. Cloud computing is a resource allocation method based on demand allocation. Its application in PE may improve the current shortcomings. Based on the above literature, this paper mainly focuses on the new PE curriculum model based on PE cloud computing.

\section{METHODOLOGY}

\section{A. Definition of cloud computing}

Cloud computing is a virtualized pool of resources caplable of being invoked, which can be reconfigured according to load dynamics to achieve optimal use. Users and services provider first of all contract the service level protocol, and users use the service in a paid or free mode. 
Cloud computing can dynamically allocate storage, computing, memory, network and other resources by user requirements through virtualization technology. Users can quickly and flexibly request and purchase service resources and expand processing capability according to actual needs. Users can use a variety of client software to call cloud computing resources through the network. The use of service resources can be monitored and reported to users and service providers. Automatic detection of failure nodes, through the redundancy of data, can continue to work and provide high quality services, to meet the service level agreement (SLA) requirements.

\section{B. The basic framework of "PE education cloud"}

The design of "PE education cloud" is based on cloud computing technology. According to the general laws and principles of physical education in colleges and universities, the overall upgrading is made for the original college physical education curriculum mode. The basic framework of "PE education cloud" is shown in Fig. 1.

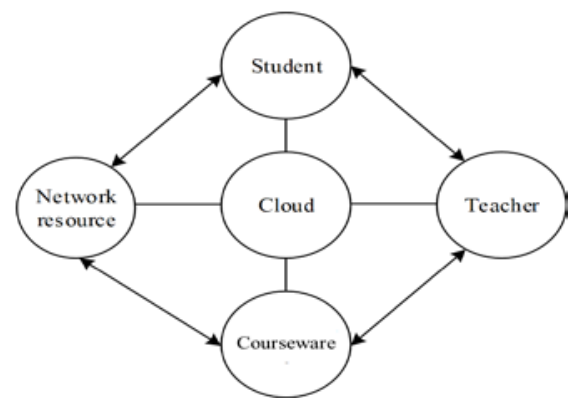

Because the users of "PE education cloud" only aim at students in various universities temporarily, the large capacity storage devices in university computer rooms are used as servers or small network servers are rent to meet the needs of "PE education cloud" for hardware. The software runs the system by a number of modules. First of all, the database management software that manages student and teacher data, which is embedded in the server terminal. Secondly, the client is authorized to give the teacher the corresponding operation authority. The last is the client authorized to the student, and the corresponding operation authority is also given. The client includes the client of the mobile phone software, the client of the tablet computer software, the client of the web page and the client of the computer software. Students and teachers only need to download system software on the corresponding smart devices and $\log$ in to the system with a given user name and password.

Through its user name and password, the teacher can log in to the client in the designated domain name of the web page or in the system software, and its functions and permissions are shown in Fig. 3 below.

Through its user name and password, the student can log in to the client in the name of the web page or in the system software as student ID. Its function and permissions are shown in Fig. 4.

Fig. 1. The framework of PE education cloud

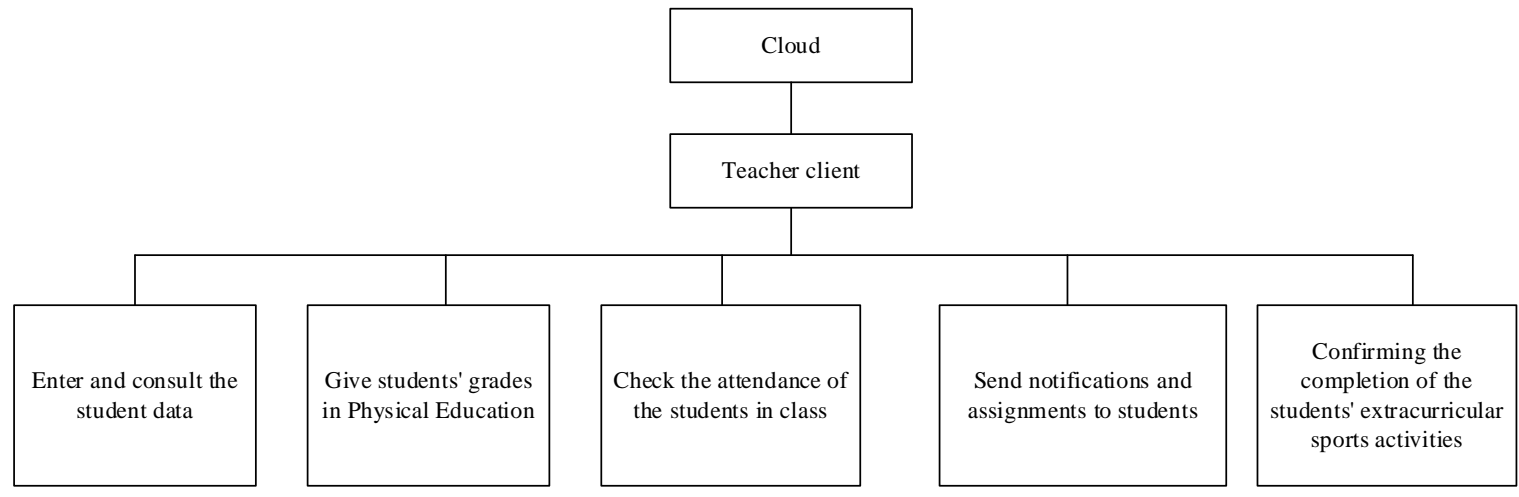

Fig. 2. Teacher client function

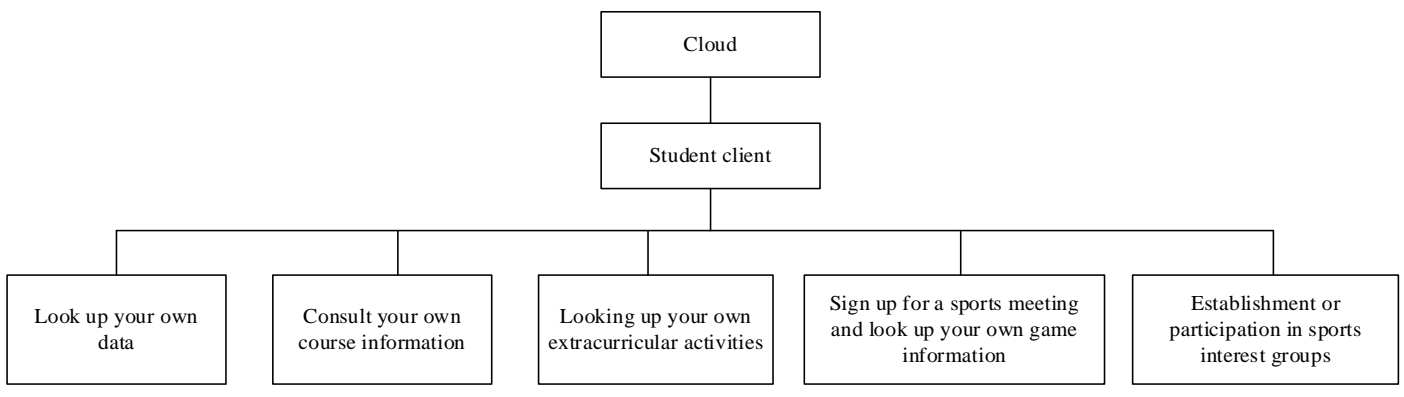

Fig. 3. Student client function 


\section{RESULTS AND DISCUSSION}

\section{A. Registration and data entry}

After the registration of new enrolment, the data of each freshman were recorded into the database, including the basic information of the name, the school number and so on. After the beginning of school, a complete physical test was carried out for the freshmen. The content of the physical test was carried out according to the National Standards for Physical Examination of College Students. After the test, the teacher checked the students' achievements and recorded the database as the "basic data" of the students. After the teacher recorded the data, the system automatically grouped the students according to the test results of the students to ensure that the students with similar physical qualities were divided into a group. PE teaching was carried out according to the group and the different teaching contents. The load and strength of the physical education class were arranged for the students of different groups. Students can view and check their basic data through the students' clients. If there are problems with the data, they can contact the teacher to check and modify the records. Student registration and course selection are shown in Fig. 4.

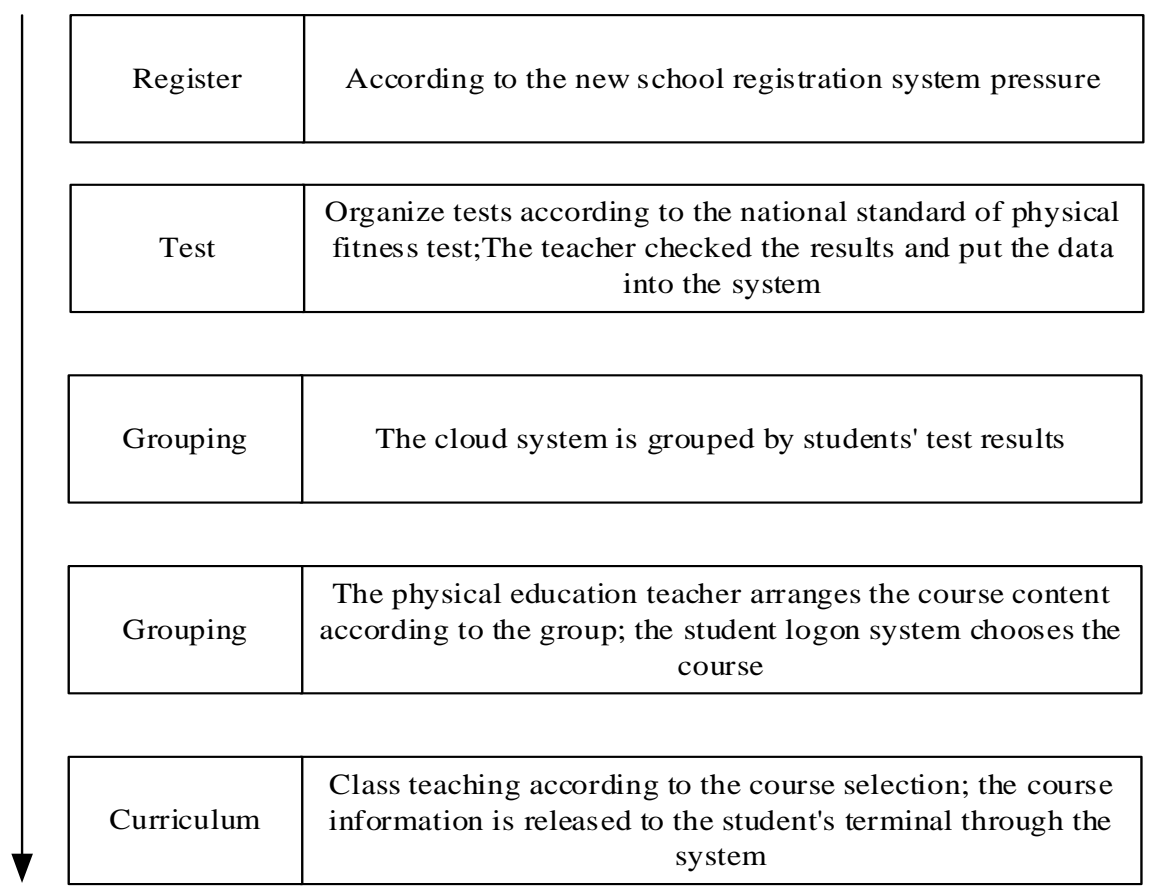

Fig. 4. Student registration and course

\section{B. Curriculum mode}

When the semester begins, according to a grouping of the system for students and the number of each group, questionnaires were issued to students in each group and the questionnaire contained all preschool opened elective courses and the skill levels of related courses that the students have. The system, based on the results of questionnaire data analysis, arranged compulsory course and elective courses for each group. Students could log in to the system and selects the elective courses within the specified groups. After completing the course selection, the cloud system automatically generated classes and publicized to teachers and students. Students can query their class time, place and teacher of a course through the system, while teachers obtained data permissions of the class. Each class automatically formed a class group, and the teacher can publish the course information, the homework and the emergency notice to the students in the group. The information sent by the teacher was quickly conveyed to the students by the way of the mobile client pushing. Students can also leave messages and questions to class teachers through the system. In the course of class, the smart mobile terminals (including smart phones and tablet computers) installed in the teacher's system can replace the roster for attendance, recording and grading. The student situation in the class can synchronize with the cloud and record the database at any time through the teacher's client.

\section{Teaching contents}

PE teachers can issue A-E level open class in the cloud to guide students in terms of extracurricular physical exercise, and the content of the open class is not limited (related to PE activities), similar to lectures. Students in group A-E sign up in the cloud and participate. Students can choose teachers and curriculum contents according to their interests and needs. Each student must attend an open class every semester. The number of participants is not limited, the more the better. And the number of attending public classes is included in the evaluation system. The main contents of the teaching are shown in TABLE I. 
TABLE I. TEACHING CONTENTS

\begin{tabular}{c|c}
\hline Groups & Teaching contents \\
\hline A & $\begin{array}{r}\text { Train sports skills and sports tactics, PE competition rules, and scientific fitness methods to improve the teaching content. At the same time, cultivate } \\
\text { the students' ability to appreciate sports, and cultivate their specific ability to referee under certain conditions. }\end{array}$ \\
\hline B & $\begin{array}{c}\text { Sports skills, scientific fitness methods and a small number of quality exercises to consolidate the teaching content. At the same time, consolidate the } \\
\text { students' interest in PE and sports, so as to further stimulate the internal motivation and to help them form good sports habits. }\end{array}$ \\
\hline C & $\begin{array}{c}\text { A small amount of sports skill learning, scientific fitness methods and a large number of targeted quality exercises to consolidate the foundation for the } \\
\text { purpose of teaching content. At the same time, we should focus on the training of students' PE cognition, stimulate the sports motivation of the students } \\
\text { and help them develop good sports habits. }\end{array}$ \\
\hline D & $\begin{array}{c}\text { Scientific sports fitness methods and all kinds of pertinent quality exercise to improve the health of the body for the purpose of teaching content. At the } \\
\text { same time, we should focus on the training of students' PE cognition, stimulate the PE motivation of the students and help them develop good sports } \\
\text { habits. Meanwhile, instruct the students' diet and rest under certain conditions. }\end{array}$ \\
\hline E & $\begin{array}{c}\text { Targeted physical activities or teamwork activities for the purpose of rehabilitation. Promote the physical and mental health of the students in this group } \\
\text { and help them restore normal physiological functions. }\end{array}$ \\
\hline
\end{tabular}

\section{Comparison and analysis of "PE education cloud" and} traditional mode

"PE education cloud" makes class division and grouping teaching of students according to physical quality, and implements the principle of distinction in the PE education. The students with similar physical quality are classified into a class for learning, which can facilitate the teachers to arrange the teaching contents and the load strength. Under the condition of unchanged PE Teachers' workload, it is necessary to strengthen the targeted nature of the classroom and improve the efficiency of physical education.

In terms of teaching content, the concept of "PE education cloud" believes that teaching content should serve students' extracurricular sports activities. The reason is what really plays a role in students lies in the PE extracurricular activities, and only extracurricular activities can meet students' PE needs. In the environment of cloud computing system, we can pay more attention to the needs of students, and resources allocation on demand. The content of physical education is not only in form and location, but also more flexible, diverse and efficient.

\section{CONCLUSION}

This paper mainly focuses on the research about the new PE curriculum model based on PE cloud computing. First of all, we introduce the basic framework of cloud computing and "PE education cloud", and design the running mode of "PE education cloud" on this basis, including registration and data entry, as well as curriculum mode and teaching content. Eventually, "PE education cloud" is compared with the traditional mode and analyzed. The results showed that: "PE education cloud" made class division and grouping teaching of students according to physical quality. In the condition of the constant workload of physical education teachers, we strengthen the classroom targeted nature and improve the efficiency of the physical education course. Under the "PE education cloud" environment, the development of physical education curriculum can pay more attention to the needs of students, and resources allocation on demand. The content of physical education course is not fixed in form and location, but more flexible, varied and efficient.

\section{ACKNOWLEDGMENT}

The authors acknowledge the support from Shaanxi Normal University.

\section{REFERENCES}

[1] Encalada, W. L., Sequera, J. L. C. "Model to Implement Virtual Computing Labs via Cloud Computing Services”, Symmetry, Vol.9, No.7, pp.117. 2017.

[2] Radchenko, G. I. "Model of problem-oriented cloud computing environment”, Proceedings of Isp Ras, Vol.8, pp.275-284. 2015.

[3] Ullah, S., Zheng, X., Zhou, F. "TCLOUD: A New Model of Data Storage Providing Public Verifiability and Dynamic Data Recovery for Cloud Computing”, Journal of Software Engineering \& Applications, Vol.6, No.3, pp.23-28. 2015.

[4] Huang, Z., Huang, J. "Personalized Overseas Chinese Education Mode Based on Map-Reduce Model of Cloud Computing”, International Journal of Emerging Technologies in Learning, Vol.11, No.4, pp.16. 2016.

[5] Sharma, P., Singh, R. R. "Three Level Cloud Computing Security Model”, International Journal of Computer Applications, Vol.119, pp.29-33. 2015

[6] Chen, H., Zhu, X., Guo, H. "Towards energy-efficient scheduling for real-time tasks under uncertain cloud computing environment”, Journal of Systems \& Software, Vol.99, No.2, pp.20-35. 2015. 